\title{
Lithofacies classification based on open hole logging using ternary diagram techniques
}

\author{
Gamal Ragab Gaafar ${ }^{1}$ M. Mehmet Altunbay ${ }^{1}$
}

Received: 19 October 2018 / Accepted: 19 March 2019 / Published online: 2 April 2019

(c) The Author(s) 2019

\begin{abstract}
The composition of the sandstone reservoir in Malay Basin sequences is dominated by sand size fraction followed by silt and clay sizes, respectively. Depositional environments in these types of sediments controlling the sand, silt, and clay fraction distribution where the proximal part of the delta characterized by more sand than silt and clay due to high energy, however, the distal part tend to have fines from silt and clay rather than sand fractions. To date the facies and lithofacies identification and classified based on the description of core analysis, which is always limited due to cost of the core samples. To minimize the uncertainty due to minimum core, the current approach was used to help the geoscientist to identify the lithofacies classification based on ternary diagram. The proposed approach is to use the ternary diagram to identify and classify the lithofacies based on the clay, silt, and sand volume produced from well logging interpretation including traditional logs and NMR technology. The fractions of the sand, silt and clay can be calculated from openhole logging based on gamma ray, density and neutron logs using the PETRONAS algorithm SSC model to compute the volume of the three fractions (sand, silt, and clay). The volume was calibrated with XRD data and sieve analysis. Ternary diagram was used to identify the lithofacies association for the reservoir interval which showing a good match with rock typing identified from porosity/permeability of core data. NMR technology used to derive grain-size-distributions in contrast to core analysis, NMR provides a continuous along hole profile of grain-size-distributions which have match with LPSA and sieve analysis, which can be utilize a continuous grain-size-distribution profile. Based on the $T_{2}$ cutoff we can easily define clay, silt and sand volumes. The study was conducted blindfolded, without initial reference to core studies, to test the robustness of the methodology. Ternary diagram considered as a good tool for lithofacies association in the interval where no core date. The defined sand, silt, and clay volumes normalized to $100 \%$ were used to compute the actual volume of each then input into the ternary diagram to identify the lithofacies association. The proposed model will help to minimize the uncertainty as a fit-for-purpose approach by improving the lithofacies association which can be translated to rock typing to improve the facies distribution in the static model and consequently, reserve estimations.
\end{abstract}

Keywords Sand $\cdot$ Silt $\cdot$ Clay $\cdot$ NMR $\cdot T_{2} \cdot$ Ternary diagram $\cdot$ Lithofacies association

\section{Introduction}

Grain size is the most fundamental property of sediment particles, affecting their entrainment, transport and deposition. Grain size analysis, therefore, provides important clues to the sediment provenance, transport history and depositional conditions (e.g. Folk and Ward 1957; Friedman 1979). The various techniques employed in grain size determination

Gamal Ragab Gaafar

gaafargr@petronas.com.my

1 Petronas Carigali SDN, BHD, Kuala Lumpur, Malaysia include direct measurement, dry and wet sieving, sedimentation, and measurement by Laser Particle Size Analysis (LPSA), XRD analysis. These methods describe widely different aspects of 'size', including maximum caliper diameter, sieve diameter and equivalent spherical diameter, and are to a greater or lesser extent influenced by variations in grain shape, density and optical properties. For this reason, the results obtained using different methods may not be directly comparable, and it can be difficult to assimilate size data obtained using more than one method (Pye 1994). All techniques involve the division of the sediment sample into a number of size fractions, enabling a grain size distribution 
to be constructed from the weight or volume percentage of sediment in each size fraction.

Sand particles are essentially small rock fragments. The quartz grains and mixed rock fragments resulting from mechanical and chemical degradation of igneous, metamorphic and sedimentary rocks may be transported to other areas and later transformed into sandstones.

After the loose sediments of sand, clay, carbonates, etc., are accumulated in a basin area they undergo burial by other sediments forming on top. The vertical stress of the overlying sediments causes compaction of the grains. Transformation into sedimentary rocks occurs by lithification, or cementation, from minerals deposited between the grains by interstitial water. The main cementing materials are silica, calcite, oxides of iron, and clay. The composition of sandstones is dependent on the source of the minerals (igneous, metamorphic, or sedimentary) and the nature of the depositional environment (Tiab and Donalson 2015).

\section{Sand silt clay model (SSC)}

The data indicate that silt size particles (sand $\geq 63 \mathrm{~mm}$, silt $=2-63 \mathrm{~mm}$, clay $\leq 2 \mathrm{~mm}$ ) were predominant for most samples, which were fitted textural classes sample groups (Shepard 1954). One group included silt and clayey silt and the other group encompassed sandy silt, silty sand, and sand which can be grouped into different lithofacies association.

Application of a binary sand-shale litho-porosity model (Fig. 1) suggested that effective porosity, $\Phi_{\mathrm{e}}$, should approach zero in the area of the apex of the boomerang distribution on a typical neutron-density cross plot (Heavysege 2002). Core plug samples from this same facies (in the Malay basin) have measured porosities in the range of $10-15 \%$. Since core porosity was assumed to represent effective porosity, $\Phi_{\mathrm{e}}$, then it was assumed that the binary model

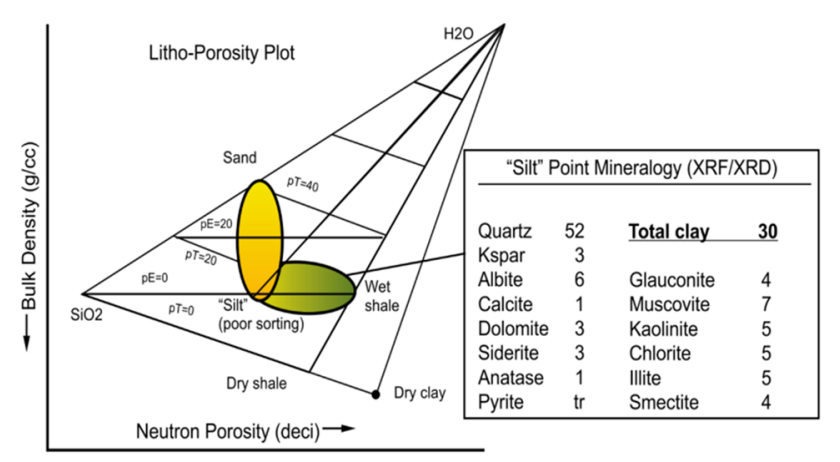

Fig. 1 Neutron-density cross-plot representing sand-silt-clay boomerang shape and XRF/XRD for core samples in the Malay Basin (Heavysege 2002) was underestimating effective porosity, $\Phi_{\mathrm{e}}$. At the same time, sieve data revealed the presence of a significant amount of silt-sized grains, typically in the order of 30-60\%. It was concluded that a binary sand-shale litho-porosity model was inappropriate for these silty reservoirs, and that more effective porosity, $\Phi_{\mathrm{e}}$, needed to be accommodated. The development of silty reservoir models had been spawned. In the Malay Basin model, the silt was accommodated at the expense of clay minerals, or shale. As a consequence, the locally used silty reservoir models have underestimated the amount of clay minerals associated with the silt-sized grains in the low-energy facies at the apex of the boomerang. Recent core studies have included petrographic descriptions (TS, SEM), as well as XRD, XRF, wet chemistry and NMR. All have defined the presence of clay minerals (20-40\%) at the silt point (Gaafar et al. 2016).

This paper focuses on the volumetric sand-silt-clay calculation technique; details on porosity and water saturation will be included in a later publication.

This model is developed by PETRONAS to solve the problems encountered in analyzing most of reservoirs in Malay Basin. This type of reservoir generally consists of fine to very fine grained sediments (silt) with low formation water salinity. In this model, the three main groups of particle sizes of lithological components; Sand, silt and clay sized particles are captured, based on the most of core data acquired in Malay Basin.

The model has been developed from the density-neutron cross-plot to determine the lithology fractions and the porosity of the rocks. The cross-plot of density-neutron data which is plotted through water bearing sandstone, siltstone, and claystone section in Malay Basin shows a shape like a "boomerang" (Kuttan et al. 1980). In general, the data points sit on the left limb of this boomerang is characterized as a reservoirs and the ones sit on the right limb as non-reservoirs. A line called "silt line" is drawn separating these two groups.

The boomerang shape of data points on the cross-plot is skewed and distorted by the amount of light hydrocarbon in the reservoir and the quality of hole condition. Consequently, it is necessary to correct for such influences before attempting any quantitative interpretation.

By placing the boomerang shaped data points into a specific triangle lines, the fraction of sand, silt, and clay sized components which represent the lithology fractions of the formation/reservoir can be determined. The lithology fractions are derived based on the amount of dry components of sand, silt, and clay sized rocks (Choo 2010).

The fractions of these dry components, called as dry sand, dry silt and dry clay volumes $\left(V_{\mathrm{sn}}, V_{\mathrm{si}}, V_{\mathrm{dc}}\right)$, are determined from the relative distance of projected data point on matrix line to quartz, dry silt, and dry clay points. 
Density and neutron log data provide individually useful porosity logs, but more information can be extracted if they are analyzed simultaneously. A density-neutron cross-plot for a well-stratified clastic sequence (Fig. 2) shows two distinct clusters that merge to form the shape of a boomerang. One cluster (the short arm of the boomerang) mainly represents sandy reservoir intervals, whereas the other arm represents non-reservoir (shale) intervals. Within the reservoir cluster, both porosity and permeability decrease from the uppermost tip of the cluster to the apex of the boomerang. Core data suggests this trend is related to increasing clay and silt content associated with low-energy sedimentary deposits. The distribution of data points on the cross-plot is, therefore, an important source of information about lithology (Choo 2010).

The clean sand line (Fig. 2) describes low gamma-ray sand deposits of variable grain size and variable sorting. Data points that fall below this line indicate the presence of clay and silt, which contain neutron-sensitive minerals and considerable amounts of bound water. In this paper, clays are defined either as total clay, or as wet clay that contains clay-bound water (CBW). Silt refers to silt sized particles of various minerals, including feldspars and micas. Silt has no CBW, but does have capillary bound water associated with its large surface area (Choo 2010).

The relative volumes of sand, silt and clay are calculated as a function of $\beta$, the angle between the clean sand line $(\beta=0)$ and the line joining the theoretical water point (point 1, 1 of Fig. 2) to the data point. The quantitative

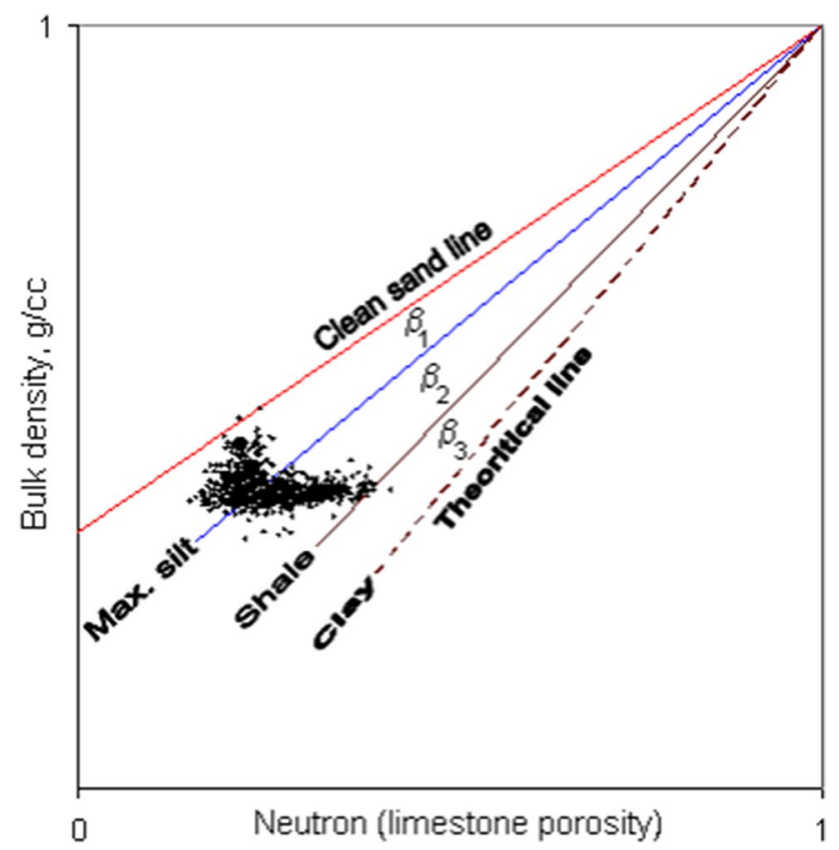

Fig. 2 Lithology model for sand, silt and clay identification, and quantification using density-neutron log data (Choo 2010) responses of clay and silt are based on core observations from X-ray diffraction data (XRD), petrographic studies, and sieve analyses. Typically, the clay line has a characteristic's' shape. Clay content is generally low in the reservoir cluster and becomes dominant in the non-reservoir cluster. Silt data points show a bell-shaped distribution, typically with a peak when silt accounts for $\sim 60 \%$ of total rock matrix.

The calibration of log data to core data is determined by and the four lines shown on Fig. 4.

1. The clean sand line $(\beta=0)$ represents a water-filled clayfree sandstone.

2. The maximum silt content line $(\beta)$ coincides with the apex of the data point boomerang.

3. The shale line $\left(\beta_{2}\right)$ is based on density-neutron $\log$ cross-plots over a massive shale formation.

4. The theoretical $100 \%$ clay line $\left(\beta_{3}\right)$ is used to fine tune the interpretation to bring out the observed characteristics of massive shale formations.

This lithological model is simplistic, but has provided results that agree well with core data from wells drilled in fluvial, deltaic-fluvial, marine, and turbidite environments, and at different depths of burial. If core data are available in a particular area, the model can be easily finetuned by adjusting $\beta_{1}$ and/or $\beta_{3}$. Increasing (decreasing) $\beta_{1}$ accounts for smaller (larger) amounts of both clay and silt in potential reservoir formations. The effects of changes to 3 are generally restricted to non-reservoir lithologies.

The final lithology interpretation of the sand, silt, clay volume as estimated by SSC model as presented in Fig. 3, where we have the raw data GR, resistivity, density-neutron, total and effective porosity calibrated by core porosity, estimated permeability using Chiew equation (Choo 2010) calibrated by core permeability, and last column where the volume of the sand, silt, and clay volume as estimated from logs as explained before calibrated by XRD, and Sieve analysis data.

\section{NMR determinations of sand, silt, and clay}

NMR was used to validate results by transferring pore-size distribution to grain size distribution. As discussed earlier, for simplicity, this research uses the cutoff technique to divide the reservoir into clay, silt and sand sizes (Fig. 4). Figures 5 and 6 show cumulative pore-size distribution at two different depths of the reservoir (X614 and X640 m). The plots suggest that the volume of clay, $V_{\text {clay }}$, is very low (5-20\%) compared to the volume of silt, $V_{\text {silt }},(10-50 \%)$, which is supported by the basin description by Kuttan et al. (1980) and is indicated in the sieve analysis displayed

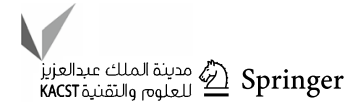




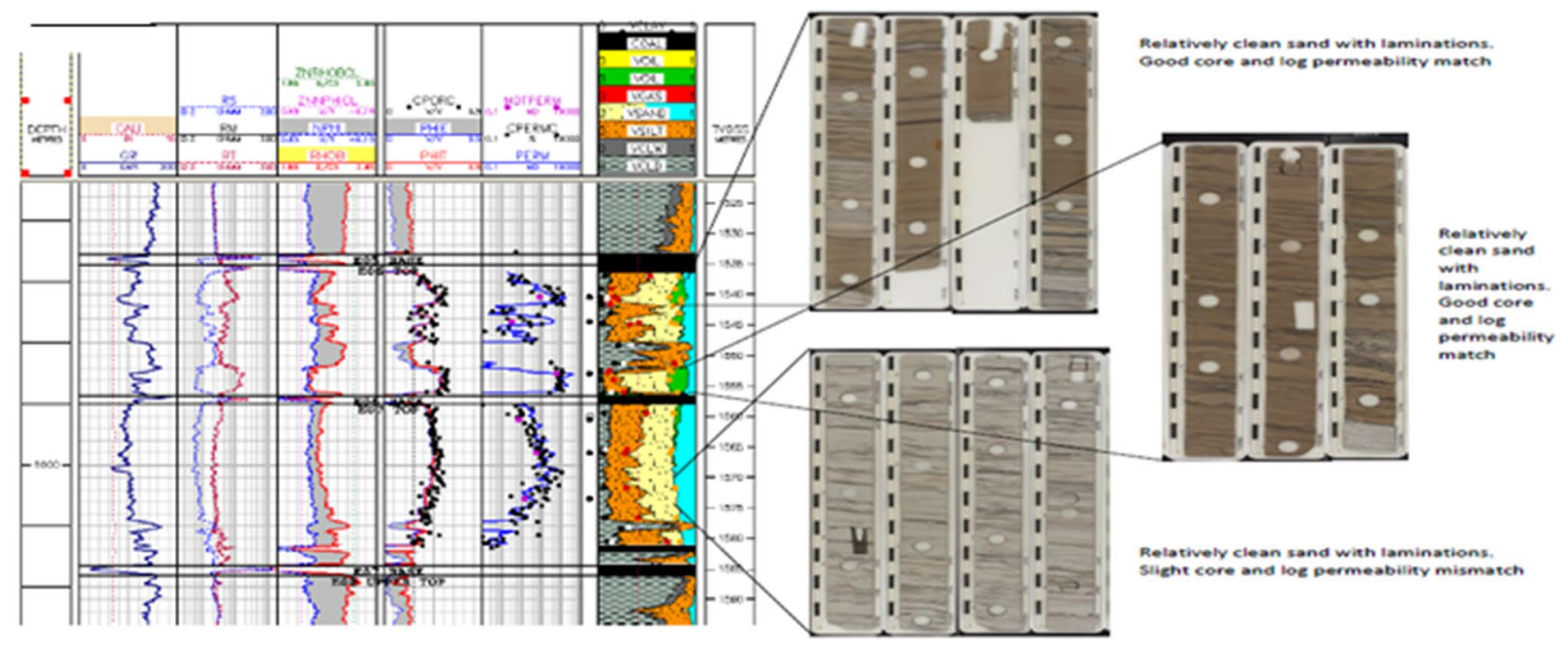

Fig. 3 Final log interpretation using SSC model calibrated by sieve analysis and XRD for lithology
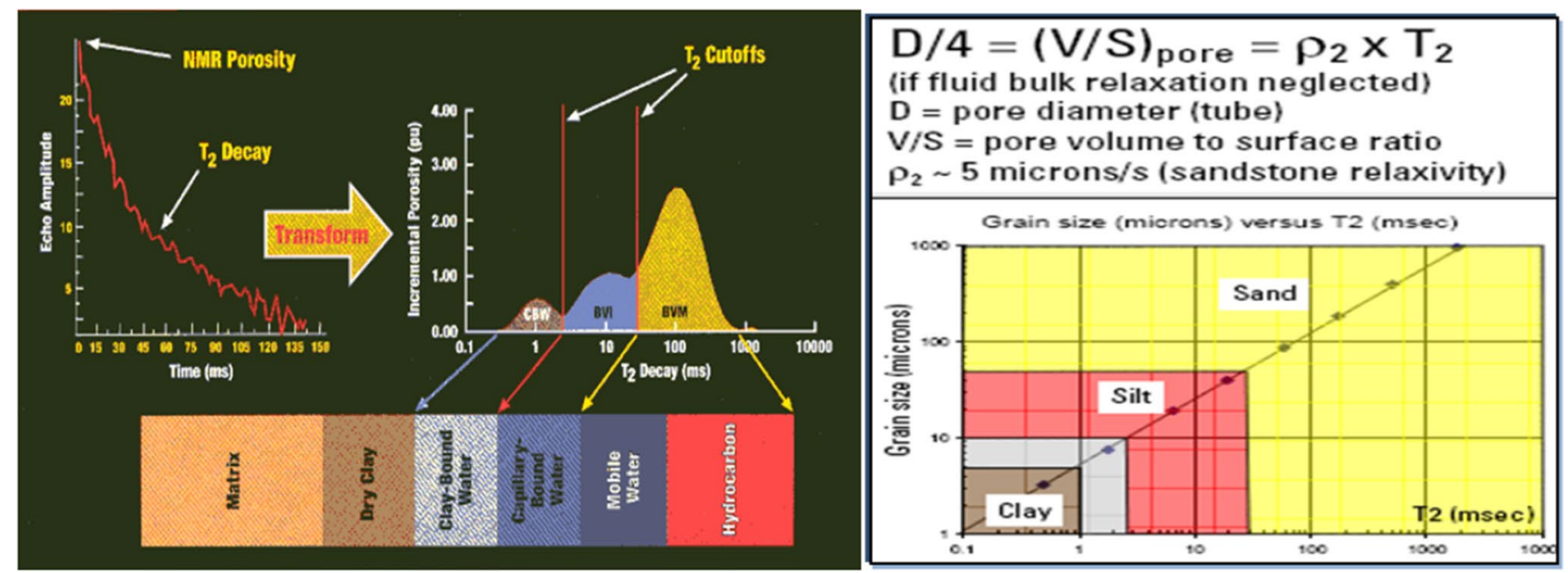

Fig. 4 NMR $T_{2}$ cut off between clay, silt, and sand

in the ternary plot (Fig. 7). When comparing results from the three different models with NMR estimated grain-size distribution and core analysis in the basin, one can easily conclude that the NMR model gives the best answer (Gaafar et al. 2016).

\section{Ternary diagram}

Ternary diagrams are useful techniques for scientific analysis of three end members systems. Ternary diagrams are used in classification and identification of lithofacies association in sandstone reservoir if there is no core taken in the interested part of the reservoir. Also can be used in petrographic analysis, and any other scientific endeavor that involves three mutually dependent components. Example of the three end member system includes percent sand-silt-clay in sandstone reservoir samples.

\section{Methodology}

Creating triangular diagram involves the following steps

1. Collect raw data for the three end members system in the form of mass, weight, or number of occurrences (frequency), 


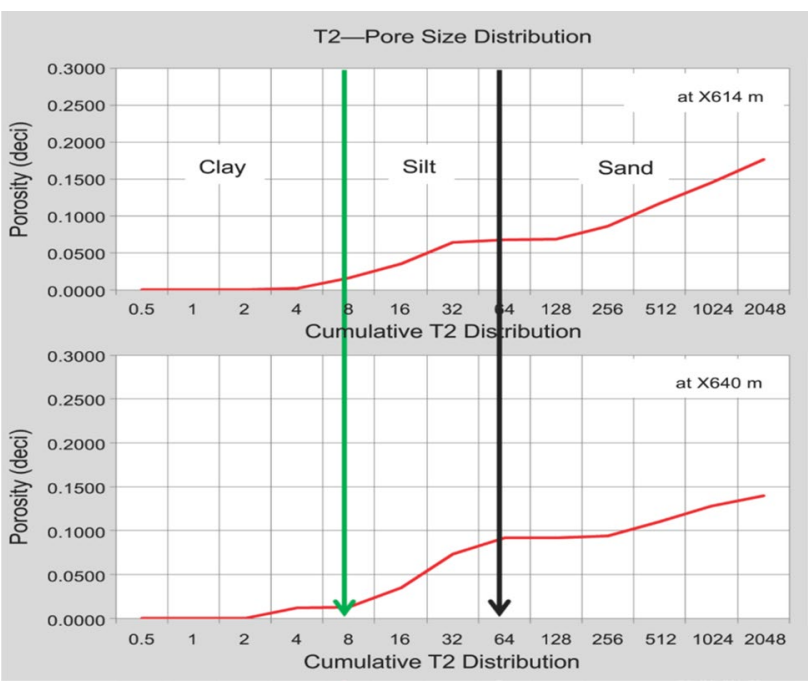

Fig. 5 NMR cumulative $T_{2}$ pore size distribution

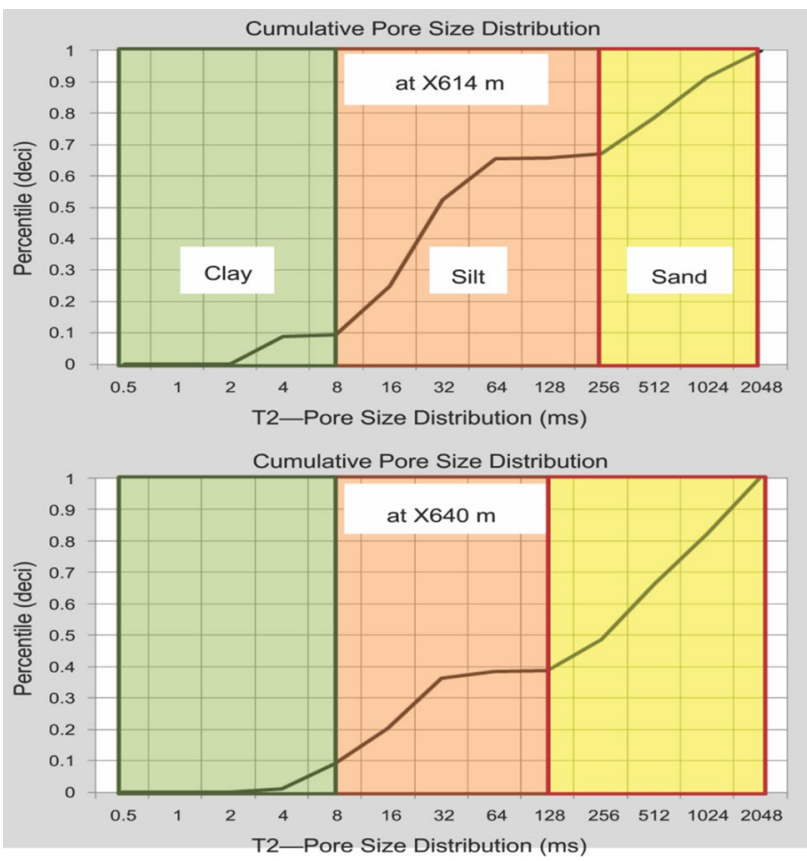

Fig. 6 Cumulative $T_{2}$ pore size distribution (percentile)

2. Re-normalize the raw data to percent of total occurrences, i.e. the three components per samples are assumed, and the percent of each of the three end components is calculated for each sample.

3. Plot the three end members on ternary diagram.

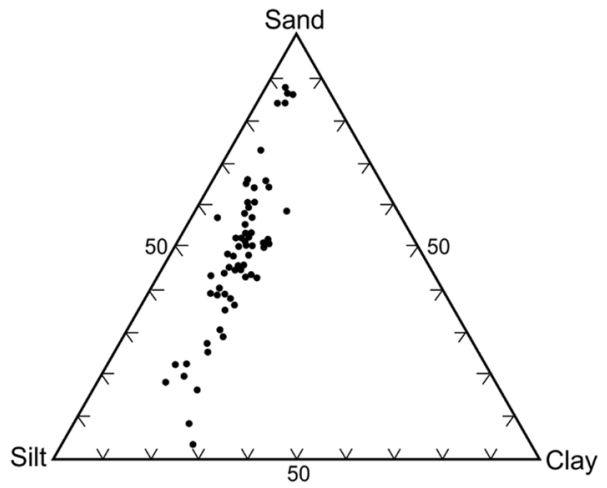

Fig. 7 Malay Basin core sieve analysis displayed in ternary diagram

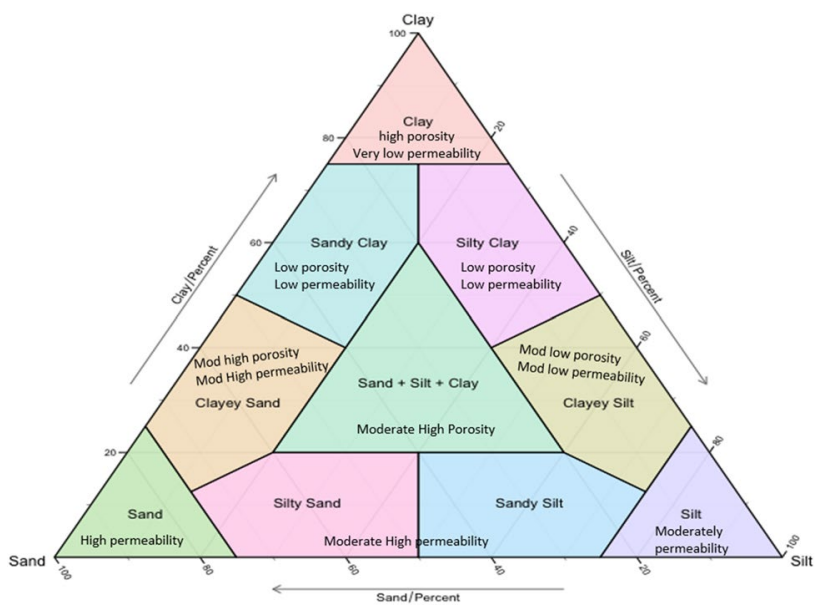

Fig. 8 Shepard ternary diagram

4. $100 \%$ of each components is represent by the apex of the angles at respective position, $0 \%$ of the component is represented by the leg opposite the angle.

5. If the total percent of the three components add up to $100 \%$, there one unique point for each sample plotted on the diagram as shown in Fig. 8.

\section{Results and discussions from case studies}

Three sets of logs acquired in different reservoirs and in very different geological environments as well as NMR data were used to test the ternary diagram to identify the lithofacies identification and classification in Temana, Baram, Sepat, Bokor, Dulang, and Limbayoung Fields.

Based on the input from the estimated sand, silt, and clay volumes from open hole logs 10 clusters lithofacies can be identified as shown in Fig. 8. Sand, silty sand, 
sandy silt, silt lithofacies can be identified based on the ratio of sand to silt ratio, silt, clayey silt, silty clay, and clay lithofacies can be identified based on the ratio of clay to silt ratios, sand, clayey sand, sand clay, and clay lithofacies can be defined based on the ration of sand to clay ratios, sand-silt-clay lithofacies can be identified based on mix from the three parameters of silt, clay, and sand.

Figure 9 presented a data set from sieve analysis from Baram field. Sand, silt, and clay volume were estimated and normalized to $100 \%$ and plotted one Shepard ternary diagram. From the ternary diagram, four lithofacies can be identified as main facies which are sand, silty sand, sandy silt and clay silt lithofacies. These lithofacies is matched with number of facies identified from core description and even $\log$ interpretation.

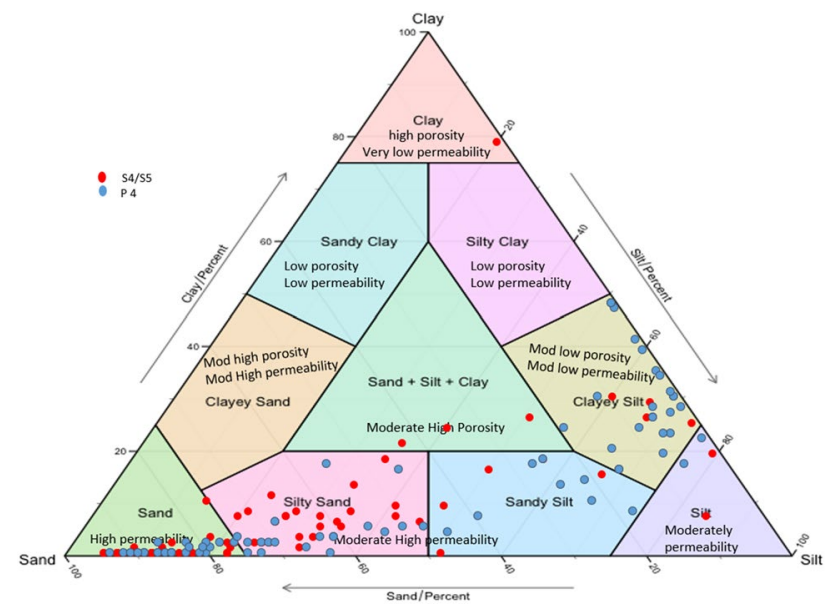

Fig. 9 Shepard sediment classification diagram for the sieve analysis data from Baram field
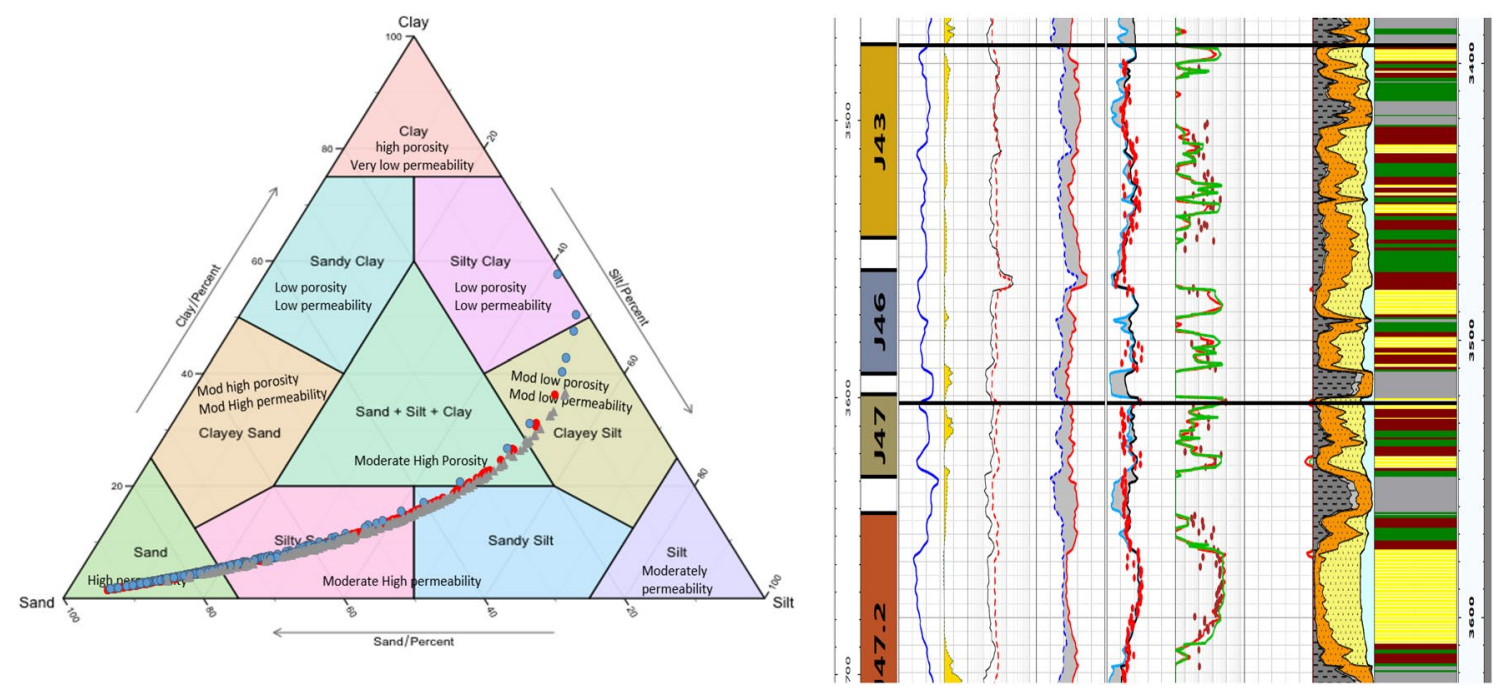

Fig. 10 Ternary diagram for the cored interval in the study well (Temana field)

\section{Case 1 (Temana field)}

Figure 10 presenting the results for the cored interval for study reservoir in three wells in the same zone where a complete log interpretation was performed using SSC model, the sand, silt, and clay volume estimated and calibrated with sieve analyses and XRD. The volume of sand, silt, and clay were normalized to be $100 \%$. The final volumes plotted on Shepard ternary diagram which help to identify five lithofacies: sand, silty sand, sand silt, sand-silt-clay, and clayey silt. These identified lithofacies have a good match with rock typing and facies descried from core. The reservoir characterized by sand, and silty sand with good quality reservoir, followed by mixed lithology with intermediate quality, the rest is low quality clayey silt reservoir.

\section{Case 2 (Baram field)}

Figure 11 presenting the results for the cored interval for the study well in the same zone where a complete log interpretation was performed using SSC model, the sand, silt, and clay volume estimated and calibrated with sieve analyses and XRD. The volume of sand, silt, and clay were normalized to be $100 \%$. The final volumes plotted on Shepard ternary diagram which help to identify five lithofacies: sand, silty sand, sand silt, sand-silt-clay, and clayey silt. These identified lithofacies have a good match with rock typing and facies descried from core. The reservoir characterized by silty sand with good quality reservoir, followed by mixed lithology with intermediate quality, the rest is low quality clayey silt reservoir. 

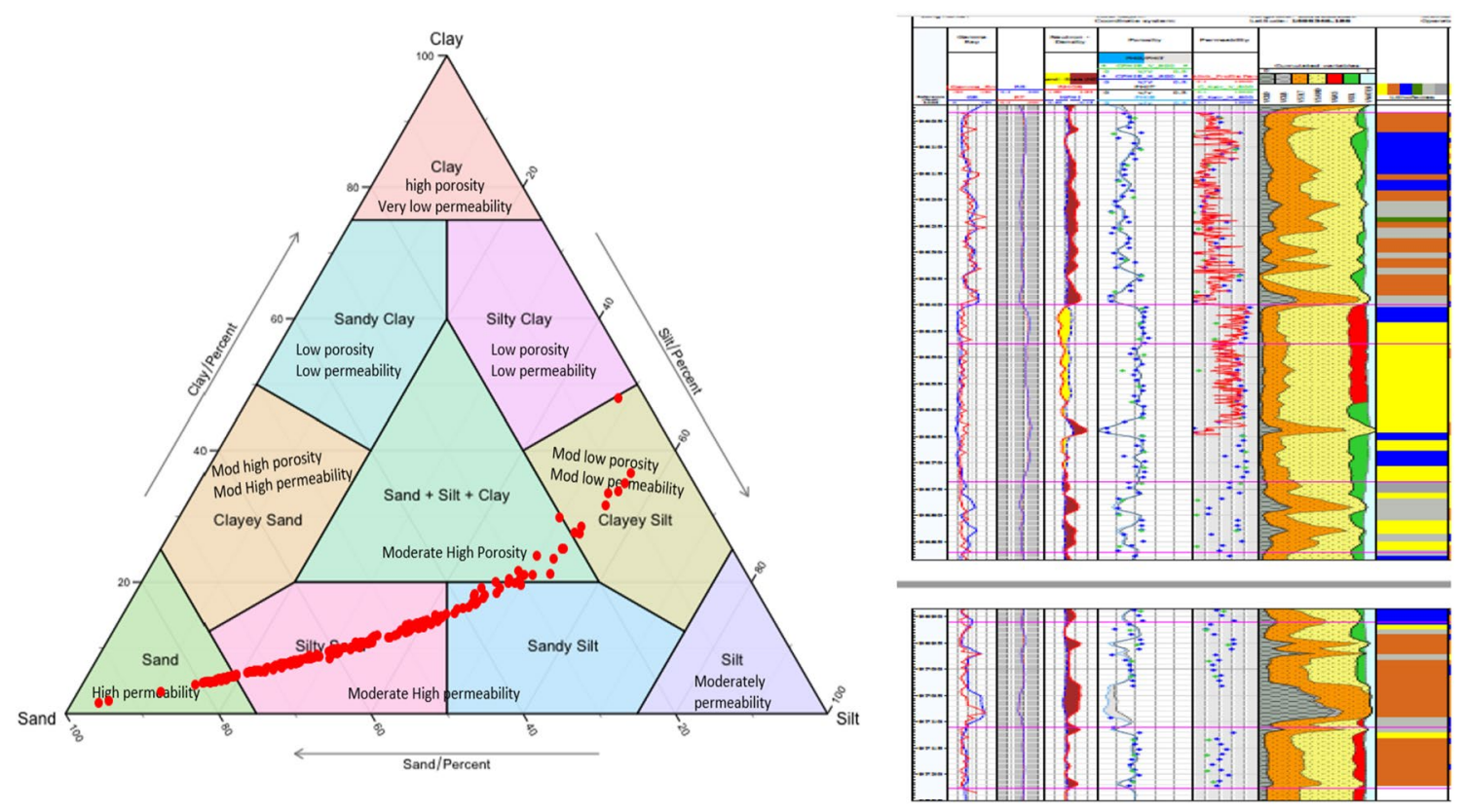

Fig. 11 Ternary diagram for the cored interval in the study well
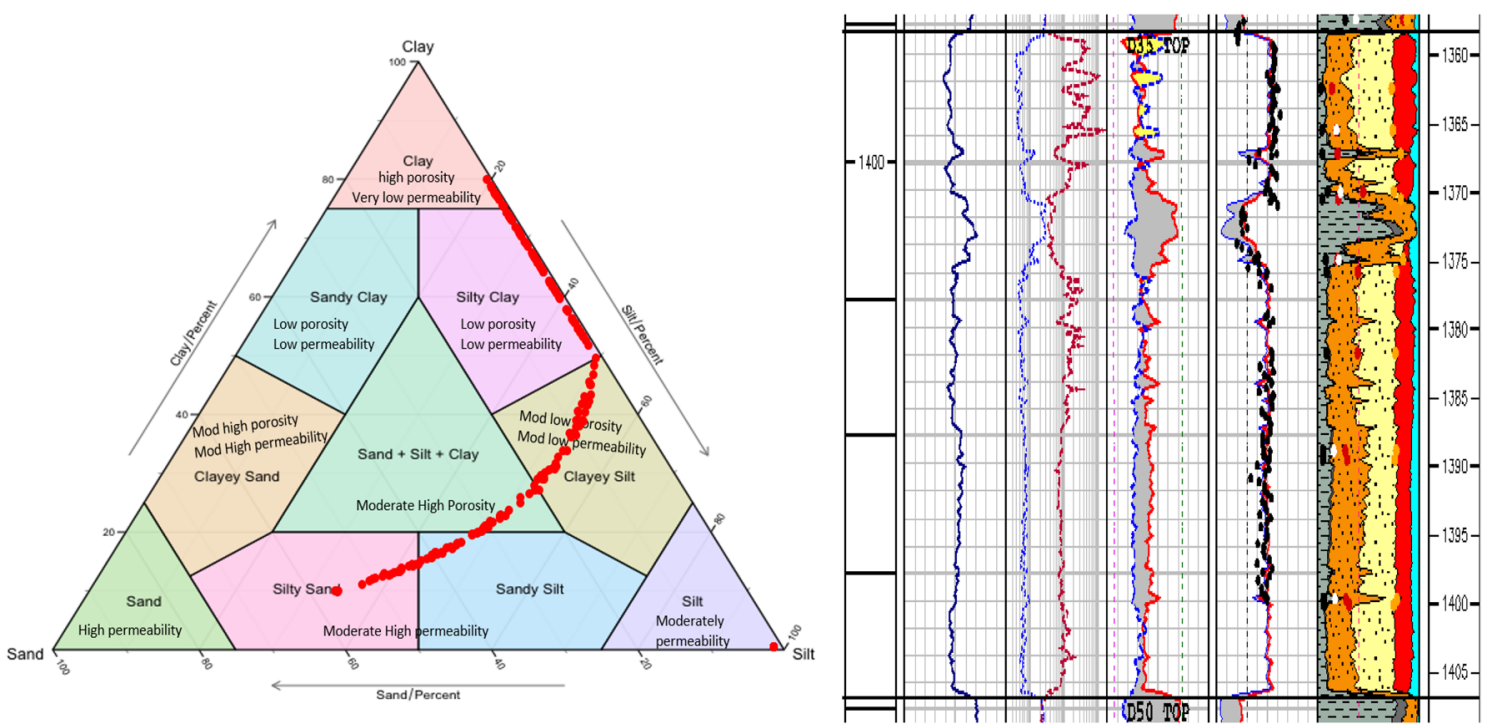

Fig. 12 Ternary diagram for the cored interval in the study well

\section{Case 3 (Sepat field)}

Figure 12 presenting the results for the cored interval for the study well in the same zone where a complete log interpretation was performed using SSC model, the sand, silt, and clay volume estimated and calibrated with sieve analyses and XRD. The volume of sand, silt, and clay were normalized to be $100 \%$. The final volumes plotted on Shepard ternary diagram which help to identify five lithofacies: silty sand, sand silt, sand-silt-clay, clayey silt, and non-reservoir silty clay, and clay. These identified lithofacies have a good match with rock typing and 
facies descried from core. The reservoir characterized by silty sand, sandy silt with good quality reservoir, followed by mixed lithology with intermediate quality, the rest is low quality clayey silt reservoir.

\section{Case 4 (Bokor field)}

Figure 13 presenting the results for the cored interval for syudy well in the same zone where a complete log interpretation was performed using SSC model, the sand, silt, and clay volume estimated and calibrated with sieve analyses and XRD. The volume of sand, silt, and clay were normalized to be $100 \%$. The final volumes plotted on Shepard ternary diagram which help to identify four lithofacies: sand, silty sand, sand-silt-clay, clayey silt, and non-reservoir silty clay and clay. These identified lithofacies have a good match with rock typing and facies descried from core. The reservoir characterized by silty sand with good quality reservoir, followed by mixed
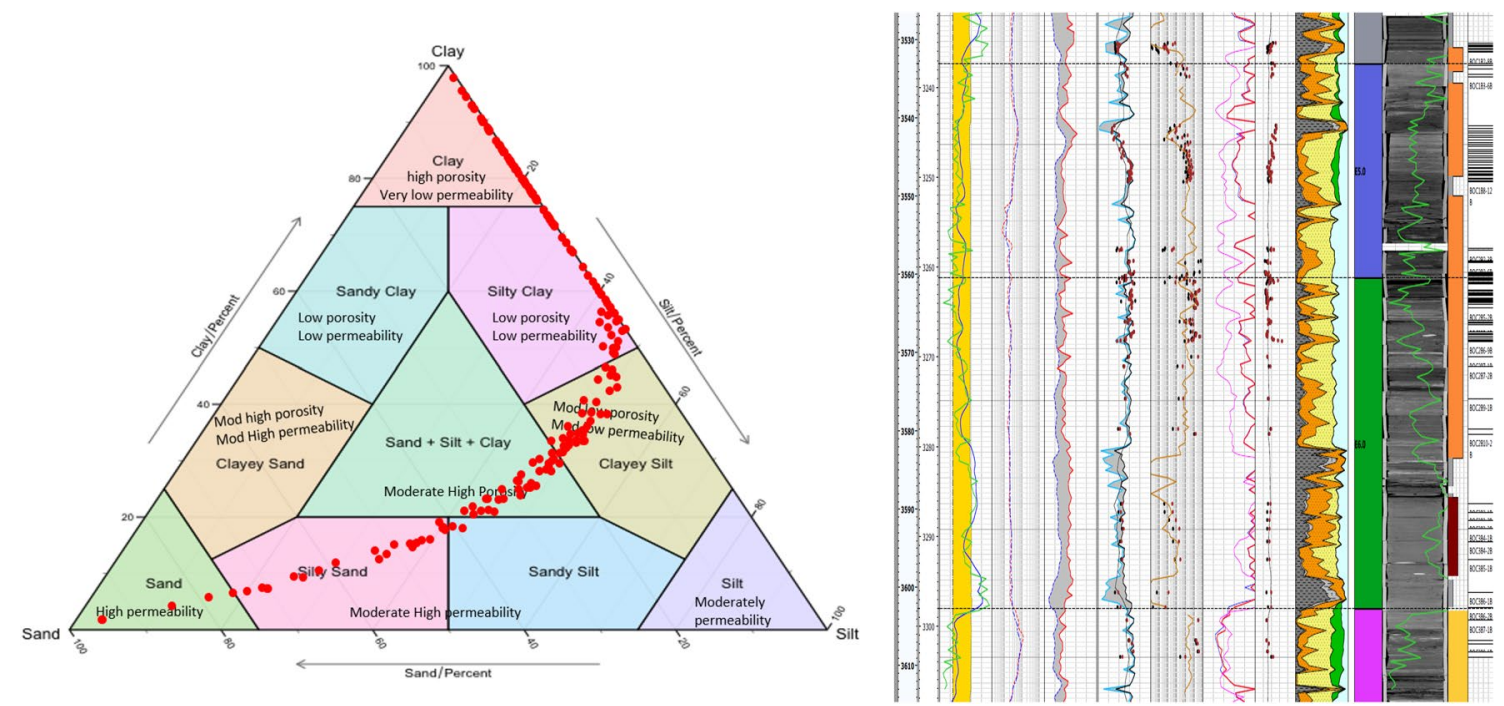

Fig. 13 Ternary diagram for the cored interval in the study well
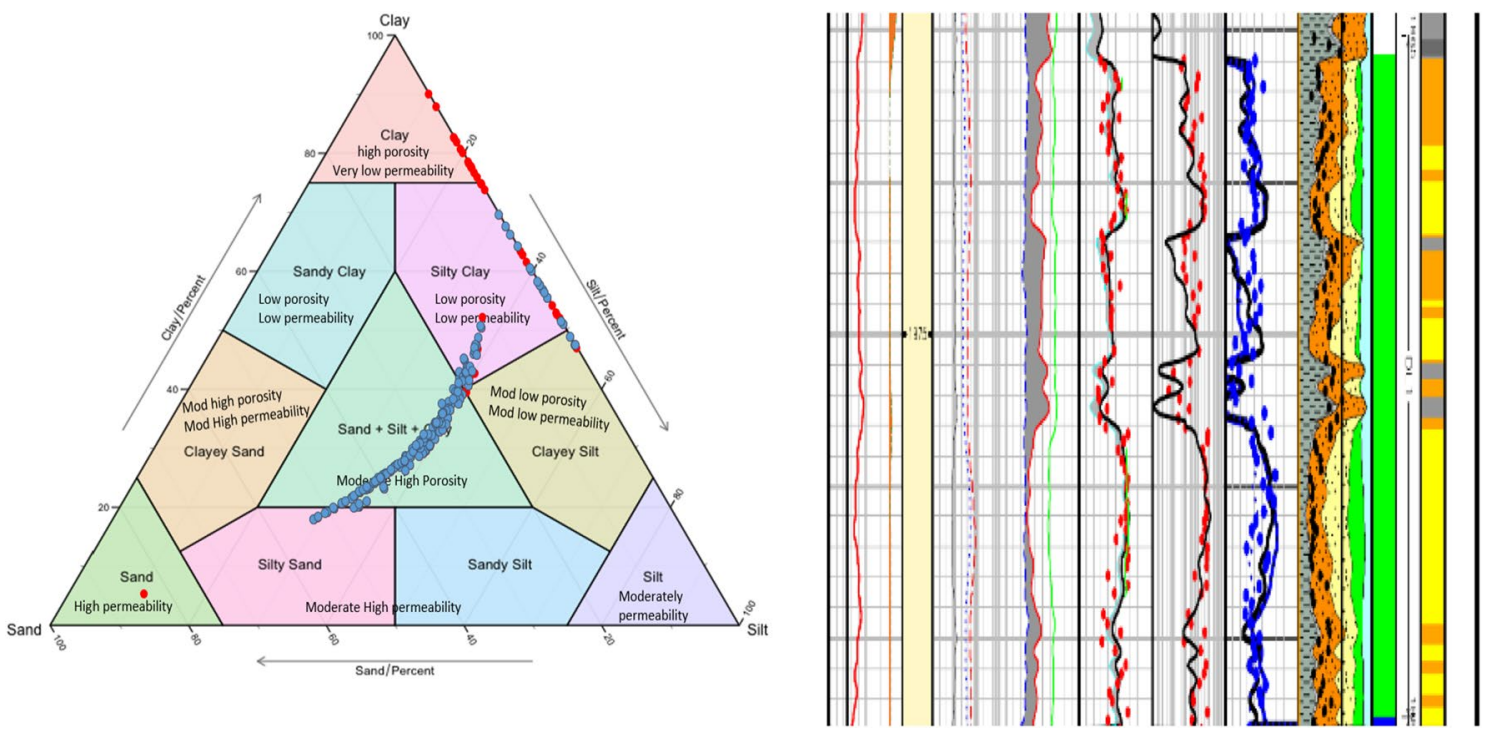

Fig. 14 Ternary diagram for the cored interval in the study well 

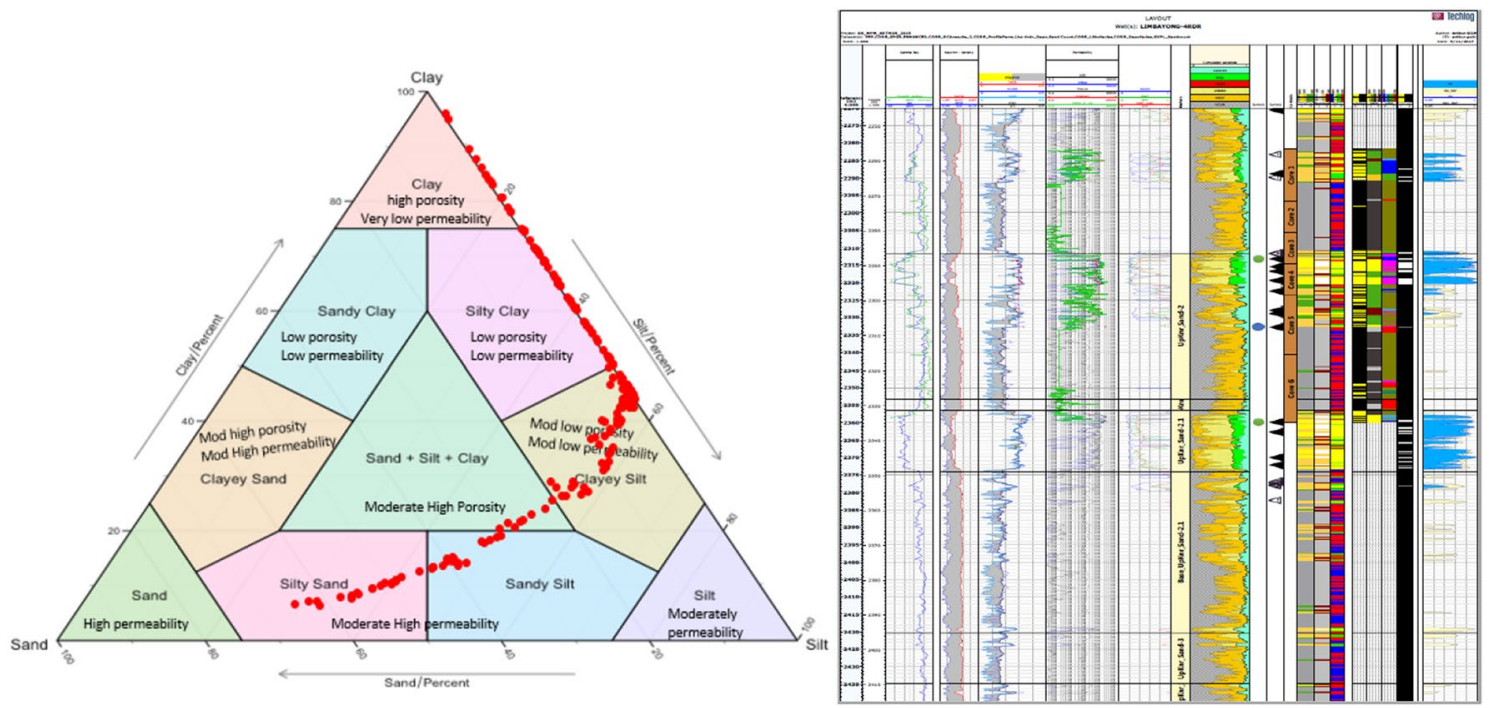

Fig. 15 Ternary diagram for the cored interval in the study well

lithology with intermediate quality, the rest is low quality clayey silt reservoir.

\section{Case 5 (Dulang field)}

Figure 14 presenting the results for the cored interval for the study well in the same zone where a complete log interpretation was performed using SSC model, the sand, silt, and clay volume estimated and calibrated with sieve analyses and XRD. The volume of sand, silt, and clay were normalized to be $100 \%$. The final volumes plotted on Shepard ternary diagram which help to identify three lithofacies: silty sand, sand silt, sand-silt-clay, and silty clay in addition to the non-reservoir part of silty clay and clay. These identified lithofacies have a good match with rock typing and facies descried from core. The reservoir characterized by mixed lithology (sand-silt-clay with intermediate quality, the rest is low quality clayey silt reservoir).

\section{Case 6 (Limbayong field)}

Figure 15 presenting the results for the cored interval for the study well in the same zone where a complete log interpretation was performed using SSC model, the sand, silt, and clay volume estimated and calibrated with sieve analyses and XRD. The volume of sand, silt, and clay were normalized to be $100 \%$. The final volumes plotted on Shepard ternary diagram which help to identify five lithofacies: silty sand, sandy silt, sand silt clay, clayey silt, and non-reservoir part. These identified lithofacies have a good match with rock typing and facies descried from core. The reservoir characterized by silty sand, sandy silt characterized by a good quality reservoir, followed by mixed lithology with intermediate quality, the rest is low quality clayey silt reservoir.

\section{Summary and conclusions}

This paper presents a new approach for the identification and classification of the lithofacies based on open hole $\operatorname{logs}$ in clastic reservoir rocks. It offers a solution to problems facing geologists when there no core taken in the interested reservoir, this approach, however, requires a change of mindset to recognize the implementation of open hole logging to solve geological issues.

NMR can play a good rule in validating sand-silt-clay calculated volumes by applying the grain-size distribution obtained from the $T_{2}$ relaxation spectrum. However, some work needs to be done to help ensure the effectiveness of the technique. Grain size distribution data from NMR logs with proper modeling and the application $T_{2}$ cut off provide a good solution to define sand, silt, and clay volume.

The proposed ternary diagram to identify and classify the lithofacies association is a very useful to tool in reservoir studies.

Acknowledgements I thank the management of PETRONAS Carigali $\mathrm{Sdn}$. Bhd. for granting permission to publish this paper. I also express my appreciation to everyone from FDP teams for their continued support and positive comments and suggestions for this paper. Last, but not least, many thanks to all my petrophysicists from FDP team for their great efforts while compiling and screening the dataset for accuracy and consistency. Special thanks for Mohamed Gamal Ragab for his time to develop the software for the ternary diagram. 
Open Access This article is distributed under the terms of the Creative Commons Attribution 4.0 International License (http://creativeco mmons.org/licenses/by/4.0/), which permits unrestricted use, distribution, and reproduction in any medium, provided you give appropriate credit to the original author(s) and the source, provide a link to the Creative Commons license, and indicate if changes were made.

\section{References}

Choo CF (2010) State-of-the-art permeability determination from well $\operatorname{logs}$ to predict drainage capillary water saturation in clastic rocks. In: SPWLA 51st annual logging symposium, June 19-23, 2010

Folk RL, Ward WC (1957) A study in the significance of grain-size parameters, J Sediment Petrol 27:3-26

Friedman GM (1979) Differences in size distribution of populations of particles among sand grains of various origins. Sedimentology 26:3-20

Gaafar GR, Eltunbay MM, Aziz SBA, Najm E (2016) Sand-silt-clay evaluation models: which one to use-a case study in the Malay
Basin, OTC-26771-MS, 2-25 March, 2016, Kuala Lumpur, Malaysia

Heavysege RG (2002) Formation evaluation of fresh water shaly sands of the Malay Basin, Offshore Malaysia. In: Presented at the SPWLA 43rd annual logging symposium, Oiso, Japan, 2-5 June. SPWLA-2002-SS

Kuttan K, Stockbridge CP, Crocker H et al (1980) Log Interpretation in the Malay Basin. In: Paper presented at the SPWLA 21st annual logging symposium, Lafayette, Louisiana, 8-11 July, SPWLA-1980-II

Pye K (1994) Properties of sediment particles. In: Pye K (ed) Sediment transport and depositional processes. Oxford, Blackwell, pp 1-24

Shepard FP, 1954, Nomenclature based on sand-silt-clay ratios. J Sediment Res 24:151-158. https://doi.org/10.1306/D4269774-2B2611D7-8648000102C1865D

Tiab D, Donalson EC (2015) Theory and practice of measuring reservoir rock and fluid transport properties, 4th edn. Gulf Professional Publishing, Houston, pp 918 (ISBN 9780128031889)

Publisher's Note Springer Nature remains neutral with regard to jurisdictional claims in published maps and institutional affiliations 